\title{
Risk Factors for Anxiety in Medical Health Workers during Coronavirus Disease 2019 in Medan, Indonesia
}

\author{
Anastasia Venny Fransisca Sipayung, Elmeida Effendy, Mustafa Mahmud Amin* \\ Department of Psychiatry, Faculty of Medicine, Universitas Sumatera Utara, Medan, Indonesia
}

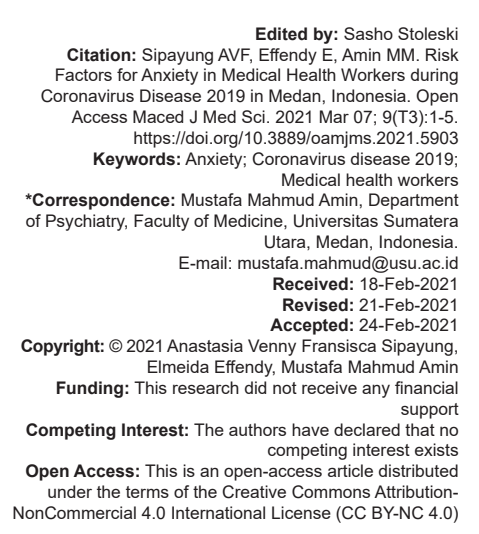

\begin{abstract}
BACKGROUND: Coronavirus disease 2019 (COVID-19) is a virus outbreak that is infecting many people almost all over the world, including Indonesia. The impact of this pandemic also affects medical health workers who are in charge of treating COVID-19 patients where they are at high risk of being infected. This causes psychological disorders such as anxiety and many factors that can become a risk for anxiety.

AIM: The aim of the study was to investigate risk factors for anxiety in medical health workers who treat COVID-19 patients.

MATERIALS AND METHODS: This study was conducted in Haji Adam Malik Hospital and its satellites in Medan, North Sumatera, cross-sectional through online survey using hospital anxiety and depression scale, anxiety subscale, from May 2020 to July 2020, 129 participants.

RESULTS: Four risk factors have a relationship to the occurrence of anxiety, such as gender, marital status, history of organic diseases, and duration of work caring for COVID-19 patients.

CONCLUSIONS: By knowing the risk factors that can cause anxiety in medical health workers, it is hoped that both the hospital management and individual medical health workers can pay more attention to and anticipate so that medical health workers can feel more secure in carrying out their duties treating for COVID-19 patients.
\end{abstract}

\section{Introduction}

Since December 2019, coronavirus disease 2019 (COVID-19) has become the largest outbreak in the form of atypical pneumonia, after 2003 , the severe acute respiratory syndrome (SARS) outbreak occurred [1]. The COVID-19 outbreak originating in the city of Wuhan, Hubei Province that was caused by SARS coronavirus 2 has been threatening human life [2], [3].

According to the World Health Organization (WHO), the development of COVID-19 since this pandemic began to spread until May 2020, worldwide there have been reported cases of COVID-19 of $5,701,337$ cases and deaths of 357,688 , involving 216 countries [4]. Whereas in Indonesia, data obtained from the Ministry of Health of the Republic of Indonesia as of May 29, 2020 had reached 24,538 positive cases and 1496 deaths [5].

Based on previous research, there were various profound and broad psychosocial impacts due to this virus outbreak, on people at the individual, community, and even international levels. At the individual level, a person is likely to experience fear of getting sick and stigma about the person being infected. For those who were older, female, more highly educated, with a higher risk perception of SARS, with moderate levels of anxiety, a positive history of contact, and experiencing SARSlike symptoms, were more likely to take precautions against infection [1].

A study conducted by Cai et al., from January 2020 to March 2020, in Hubei China, which involved 534 medical staff including doctors, nurses, medical technicians, hospital staff, using a questionnaire specially designed by Lee et al., consists of 5 parts with a total of 67 questions. From the results, it was found that there was social and moral responsibility, which encouraged them to continue working during the outbreak $(p=0.03)$, and doctors had the highest average score $(2.47 \pm 0.66)$. Medical staff was also expected to receive awards from hospital management $(p<0.001)$, and nurses were more concerned about additional financial compensation during or after the outbreak than other health workers $(p=0.002)$. In addition, nurses also felt more nervous and anxious when they were on the ward compared to other groups $(p=0.02)$. Meanwhile, doctors were more displeased with working overtime during the COVID-19 outbreak than other health workers $(p=0.02)$. Other main factors associated with stress were concern for personal safety $(p<0.001)$, concern about their family $(p<0.001)$, and concern about the patient's death 
$(p=0.001)$. Medical staff in the $31-40$ years age group was more concerned about infecting their family than any other group $(2.46 \pm 0.72)$. Worry about their own safety is also an important factor in anxiety among medical staff, especially in the 41-50 years old group. Lack of protective clothing $(p=0.0195)$ and fatigue due to increased duration of work $(p=0.03)$ also increased significantly among older staff [6].

According to a study conducted by Tan et al., from February 2020 to March 2020, in Singapore, which involved 470 health workers, consisting of 2 parts, 296 medical members (doctors and nurses) and non-medical members (allied health professionals, pharmacists, technicians, administrators, and clerical staff) totaling 174 participants, using the depression, anxiety, and stress scales (DASS-21) and the impact of events scale-revised (IES-R) questionnaires, results showed that there were participants experiencing anxiety in 68 subjects, depression in 42 subjects, stress in 31 subjects, and clinical symptoms of post-traumatic stress disorder in 36 subjects. Meanwhile, the prevalence of anxiety is higher among non-medical health workers. Likewise, the DASS-21 score and the total IES-R score were higher in non-medical than medical personnel [7].

According to a study conducted by Lai et al., January 2020 to February 2020, in China, which involved 1257 health workers in 34 hospitals, using the 9-item patient health questionnaire (PHQ-9) questionnaire for depression, the 7-item generalized anxiety disorder scale (GAD-7) for anxiety, the 7-item insomnia severity index (ISI) for insomnia, and the 22-item IES-R for the Chinese version of stress, it was found that nurses, women, frontline health workers, and working in Wuhan scored higher on the four measurement scales compared to doctors, men, second-line health workers, and working in Hubei Province. Another comparison was that between healthcare workers working in tertiary hospitals, those working in secondary hospitals reported higher scores for depression, anxiety, and insomnia. However, there was no significant difference in hospital status on stress scores [8].

According to a study conducted by Zhang et al., February 2020-March 2020, in China, which involved 2182 subjects by comparing non-medical health workers as many as 1255 subjects and medical workers as many as 927 subjects, aged 16 years and over, cross-sectional study through online survey, found that health care professionals had a higher prevalence of insomnia (38.4 vs. $30.5 \%, p<0.01$ ), anxiety (13.0 vs. $8.5 \%, p<0.01)$, depression (12.2 vs. $9.5 \%), p<0.04)$, somatization ( 1.6 vs. $0.4 \%, p<0.01$ ), and obsessivecompulsive symptoms (5.3 vs. $2.2 \%, p<0.01$ ). Medical personnel also has higher scores on filling out the ISI questionnaire, the 2-item GAD-2, the 2-item PHQ-2, and the symptom check list-90- revised ( $p \leq 0.01$ ). Among medical personnel, having a history of organic disorders was an independent factor for the occurrence of insomnia, anxiety, depression, somatization, and obsessive-compulsive symptoms ( $p<0.05$ or 0.01 ). Residing in rural areas, women, at risk of contact with COVID-19 patients were common risk factors for insomnia, anxiety, obsessive-compulsive symptoms, and depression $(p<0.01)$ [9].

From this background, COVID-19 outbreak that is currently sweeping in many countries, it has caused many psychological problems in humans, including for medical health workers in hospitals, doctors, and nurses who are in charge for caring and treating COVID-19 patients. Psychological problems that have an impact on medical personnel are often encountered that is anxiety. Factors that affect the emergence of psychological disorders, such as sociodemographic factors, working systems, and regulations that are applied to medical personnel who treat COVID-19 patients and general medical conditions that medical personnel may suffer themselves. Some of the results of the studies conducted show that there is a relationship between the above factors causing anxiety but there are also studies that are inconsistent with it. From the literature review traced by researchers, for the island of Sumatra or even in Indonesia, there is still no research found regarding the factors that influence anxiety scores among medical personnel who treat COVID-19 patients. Meanwhile, the measuring instrument used by researcher to measure anxiety scores is the hospital anxiety and depression scale-anxiety subscale (HADS-A), which from a literature review has not found any previous studies that used this measurement tool to measure anxiety scores in medical personnel who treat COVID-19 patients. The HADS questionnaire itself will be distributed using online survey by Google Forms sheet through WhatsApp application. Moving on from that background, the researcher wants to know what factors are related to the anxiety scores of medical personnel who treat COVID-19 patients.

\section{Materials and Methods}

This study was adopted a multivariate analysis with a cross-sectional design, to measure the psychological impact of COVID-19 in medical health workers using HADS-A. Distribution of questionnaire was carried out through online survey using Google Forms which aim to prevent the transmission of the virus between author and participants. This study was approved by the Ethics Committee of Medical Faculty of Universitas Sumatera Utara 257/KEP/USU/2020 and written informed consent in the Google Forms for all participants.

This study was conducted in Haji Adam Malik Hospital Medan and its satellites from May 2020 to July 2020 with the subject were doctors and nurses as medical health workers who are in charge of caring for 
COVID-19 patients. A total of 129 subjects participated. Inclusion criteria included: Male and female, doctors, and nurses who are in charge of caring for COVID-19 patients, 25-35 years of age, cooperative and have Whatsapp application in their mobile phone to be able to fill out the questionnaire. Exclusion criteria are, there are no psychotic symptoms to participants.

HADS consists of two separate subscales: Anxiety and depression scale, which contains seven statements every subscale. The anxiety scale measures the general anxiety [10], [11]. This questionnaire is not for diagnostic but only for screening anxiety symptom. HADS has been validated into the Indonesian versio. Its interrater agreement for HADS-A were 0.706 and HADS-D were 0.681 , where the value of $0.61-0.80$ means that the Cohen's Kappa agreement is good [12].

\section{Statistical analysis}

The data were analyzed by IBM SPSS 22.0 version. First, we analyzed characteristic of sociodemographic to measure the frequency of each variable. There are six independent variables in this study: Gender, occupation, education, marital status, history of organic diseases, and duration of work treating for COVID-19 patients. Second, we analyzed bivariate test. For independent variables with categorical scale, we used independent t-test if the data are normally distributed and alternative test, Mann-Whitney $U$ test, if the data are not normally distributed. For independent variables with numerical scale, we used Pearson test if the data are normally distributed and alternative test, Spearman test, if the data are not normally distributed [13]. From the result of bivariate analysis, the independent variable with $p<0.25$ can be continued to multivariate analysis. Third, we analyzed multivariate linear regression test by taking the independent variables which have $p<0.25$ from the bivariate analysis. In multivariate analysis, we used backward method. In this study, multivariate analysis was analyzed twice to find the most fit model [14].

\section{Results}

\section{Characteristics of sociodemographics}

Most subjects in characteristics of sociodemographic of gender were females, 84 subjects $(65.1 \%)$, while males were 45 subjects $(34.9 \%)$. For the variable of occupation, the most were doctors, 95 subjects $(73.6 \%)$ and nurses were 34 subjects $(26.4 \%)$. For the education variable, the highest proportion was university, 113 subjects (87.6\%) and for bachelor was 16 subjects $(12.4 \%)$. For the variable of marital status, the most were married, 76 subjects $(58.9 \%)$, while those who were not married, including divorced and separated, were 53 subjects (41.1\%). Moreover, for the history of organic diseases, there was no history of organic diseases, 104 subjects (80.6\%), while those with a history of organic diseases were 25 subjects (19.4\%). Duration of time treating for COVID-19 patients was $8 \mathrm{~h}$ (1-12) (Table 1).

Table 1: Sociodemographic characteristics of subjects

\begin{tabular}{lll}
\hline Variables & $\mathrm{n}(\%)$ & Median (min-max) \\
\hline Gender & & - \\
$\quad$ Male & $45(34.9)$ & - \\
$\quad$ Female & $84(65.1)$ & - \\
Occupation & & - \\
$\quad$ Physicians & $95(73.6)$ & \\
$\quad$ Nurses & $34(26.4)$ & - \\
Education & $16(12.4)$ & - \\
$\quad$ Bachelor & $113(87.6)$ & - \\
$\quad$ Collage/Master & $76(58.9)$ & - \\
Marital status & $53(41.1)$ & - \\
$\quad$ Married & $25(19.4)$ & - \\
Single & $104(80.6)$ & $8(1-12)$ \\
Having organic disease & - & \\
$\quad$ Yes & & \\
$\quad$ No & & \\
Duration of work & &
\end{tabular}

\section{Bivariate analysis of HADS-A scores}

HADS-A score on variable of gender was male 5 (1-9) and female 7 (1-13) with $p=0.001$. In the occupational variable, doctors $6(1-13)$ and nurses 7 (2-13) with $\mathrm{p}=0.011$. In the education variable, bachelor $6(2-12)$ and university $6(1-13)$ with $p=0.658$. The marriage variable for married subjects was 7 (1-13) and $5(1-13)$ unmarried with $p=0.001$. In the variable, the history of organic diseases, yes, has a history of organic diseases, 7.20 (3.14) and does not have a history of organic diseases of 6.16 (2.67) with a value of $p=0.165$. In the duration of work, the HADS-A score was $8(1-12)$ with a $p=0.001$ (Table 2). Hence, from the results of bivariate analysis, the variables that have $p<0.25$ are gender, occupation, marital status, history of organic diseases, and duration of work treating for COVID-19 patients, then we moved to analyze the multivariate analysis.

Table 2: Bivariate analysis of HADS-A scores

\begin{tabular}{llll}
\hline HADS-A scores & Median (Min-Max) & Mean (S.D) & $\mathrm{p}$ \\
\hline Gender & & & \\
$\quad$ Male & $5(1-9)$ & - & $0.001^{\mathrm{a}}$ \\
$\quad$ Female & $7(1-13)$ & - & \\
Occupation & $6(1-13)$ & - & $0.011^{\mathrm{a}}$ \\
$\quad$ Physicians & $7(2-13)$ & - & \\
$\quad$ Nurses & $6(2-12)$ & - & $0.658^{\mathrm{a}}$ \\
Education & $6(1-13)$ & - & \\
$\quad$ Bachelor & $7(1-13)$ & - & $0.001^{\mathrm{a}}$ \\
$\quad$ College/Master & $5(1-13)$ & - & \\
Marital status & & - & $0.165^{\mathrm{b}}$ \\
$\quad$ Married & $7.20(3.14)$ & - & $0.001^{\mathrm{c}}$ \\
$\quad$ Single & $6.16(2.67)$ & - & \\
Having organic disease & $8(1-12)$ & & \\
$\quad$ Yes & &
\end{tabular}

\section{Multivariate analysis of HADS-A scores}

By doing an analyze for multivariate analysis, the aim is to answer the hypothesis about HADS-A 
score. Variables of gender, marital status, history of organic diseases, and duration of work treating for COVID-19 patients significantly associated with HADS-A scores of medical health workers who treat COVID-19 patients as risk factors that can cause anxiety $(p<0.05)$ (Table 3$)$. For the correlation coefficient, it can be seen in the standard coefficient column (Beta), where the correlation coefficient of gender is 0.360 (positive correlation), marital status is -0.396 (negative correlation), history of organic disease is -0.193 (negative correlation), and duration of work is 0.307 (positive correlation).

Table 3: Multivariate analysis of HADS-A

\begin{tabular}{llll}
\hline HADS-A scores & Correlation Coefficients & B Multivariate Regression & $\mathrm{p}$ \\
\hline Constant & 5.399 & & \\
Gender & & 0.360 & 0.001 \\
Marital status & -0.396 & 0.001 \\
Having organic disease & & -0.193 & 0.008 \\
Duration of working & 0.307 & 0.001 \\
\hline HADS-A: Hospital anxiety and depression scale-anxiety. & &
\end{tabular}

HADS-A: Hospital anxiety and depression scale-anxiety.

\section{Discussion}

This study is a multivariate linear regression study with a predictive conceptual which aims to find relationship of several independent variables as risk factors of the anxiety to the dependent variable, anxiety score, using HADS-A. This study involved 129 subjects, medical health workers (doctors and nurses) who worked at Haji Adam Malik Hospital Medan and its satellites, who treat COVID-19 patients from May 2020 to July 2020 through online survey from Google Forms sheets, distributed through WhatsApp application. The use of online survey is aimed at preventing transmission of the virus during research process, as well as between researcher and participants by implementing one of the health regulation or protocol, social distancing.

After we did the multivariate analysis, it was found that there were four independent variables which were significant and had a relationship with HADS-A score, including gender (positive correlation), marital status (negative correlation), history of organic diseases (negative correlation), and duration of work treating for COVID-19 patients (positive correlation).

In this study, women tended to experience anxiety. This study is same as in research conducted by Lai et al., 2020, China [8] and Zhang et al., 2020, China [9]. There are many factors that can trigger anxiety, such as stress, physical conditions, genetic background, and hormonal imbalances [15]. In addition, from this study, duration of working time for medical health workers also can increase the onset of anxiety because the longer the time to treat patients, the more likely they are to be exposed to and infected with COVID19. More than that, it can also cause the chance to infect other people, such as family and co-workers.
Whereas from this study, participants who are not married and who do not have a history of organic diseases tend to reduce the risk of anxiety. Someone who is not married, probably because they do not have children, live alone or have less family responsibilities, compared to married participants. For the absence of a history of organic diseases, it can reduce the risk of anxiety because the organic diseases itself can worsen a person's recovery if exposed to COVID-19.

The strengths of this study are it is the first to be conducted in North Sumatra and even in Indonesia which investigate the risk factors for anxiety in medical health workers who treat COVID19 patients using HADS and we did it through online survey which aims to prevent transmission of the virus as researchers must obey health protocols from the government to limit activities outside or stay at home and keep social distancing. Besides that, we need to be remembered, WHO stipulates physical distancing, wearing a mask, keeping rooms well ventilated, avoiding crowds, cleaning our hands, and coughing into a bent elbow or tissue. The limitation of this study is that the researchers cannot explain to the participants the items of the questionnaire if there is difficulty in the participants to understand the meaning of the question.

\section{Conclusions}

Risk factors that can cause anxiety in medical health workers who treat COVID-19 patients include gender, marital status, history of organic diseases, and duration of work caring for COVID-19 patients. It must receive attention from both the hospital and the individual itself because this affects the health and safety of them. Some efforts that can be made include a periodic measure of psychological status using a questionnaire or interviewing conducted by the hospital administration department. Reasonable work shift arrangement, such as shorter work hours, rotating shifts for staff who work in high-risk jobs. Logistical support and accommodations for health maintenance, including scheduled rest periods, regular exercise, and nutritional meals should be provided.

\section{Acknowledgment}

The author would like to thank to:

Dr. dr. Elmeida Effendy, M. Ked., Sp. K.J. (K) and Dr. dr. Mustafa M. Amin, M. Ked., M. Sc., Sp. K.J. (K) as my lecturer and thesis supervisor, which has to support and to help the author to complete this research 
All participants, doctors, and nurses at Haji Adam Malik Hospital Medan and its satellites.

\section{References}

1. Wang C, Pan R, Wan X, Tan Y, Xu L, Ho CS, et al. Immediate psychological responses and associated factors during the initial stage of the 2019 Coronavirus disease (COVID-19) epidemic among the general population in China. Int J Environ Res Public Health. 2020;17(5):1729. https://doi.org/10.3390/ ijerph17051729

PMid:3215578

2. Lu W, Wang H, Lin Y, Li L. Psychological Status of Medical Workforce during the COVID-pandemic: A Cross-sectional Study. Amsterdam: Elsevier; 2020. p. 1-5.

3. Kong X, Zheng K, Tang M, Kong F, Zhou J, Diao L, et al. Prevalence and Factors Associated with Depression and Anxiety of Hospitalized Patients with COVID-19. New York: MedRxiv; 2020. p. 1-12. https://doi.org/10.1101/2020.03.24.20043075

4. World Health Organization. Coronavirus Disease (COVID-19) Situation Report-130. Geneva: World Health Organization; 2020. Available from: https://www.who.int/docs/default-source/ coronaviruse/situation-reports/20200529-covid-19-sitrep-130. pdf?sfvrsn=bf7e7f0c_4. [Last accessed on 2020 May 29].

5. Kementerian Kesehatan Republik Indonesia. Situasi Virus COVID-19 di Indonesia. Available from: https://www.covid19. kemkes.go.id/situasi-infeksi-emerging/info-corona-virus/ situasi-terkini-perkembangan-coronavirus-disease-covid-1929-mei-2020/\#.X6helcgzblU. [Last accessed on 2020 May 29]. https://doi.org/10.25077/jikesi.v1i1.13

6. Cai H, Tu B, Ma J, Chen L, Fu L, Jiang Y. Psychological impact and coping strategies of frontline medical staff in Hunan between January and March 2020 during the outbreak of Coronavirus disease 2019 (COVID-19) in Hubei, China. Med Sci Monit. 2020;26:e924171. https://doi.org/10.12659/msm.924171 PMid:32291383

7. Tan BY, Chew NW, Lee GK. Psychological impact of the COVID-19 pandemic on health care workers in Singapore. Ann
Intern Med. 2020;173(4):317-20.

PMid:32251513

8. LaiJ, MaS, WangY, CaiZ, HuJ, WeiN, etal. Factorsassociated with mental health outcomes among health care workers exposed to Coronavirus disease 2019. JAMANetw Open. 2020;3(3):e203976 https://doi.org/10.1001/jamanetworkopen.2020.3976 PMid:32202646Zhang W, Wang K, Yin L, Zhao W, Xue Q, Peng $M$, et al. Mental health and psychosocial problems of medical health workers during the COVID-19 epidemic in China. Psychother Psychosom. 2020;89(4):242-50. https://doi. org/10.1159/000507639

PMid:32272480

9. Stern AF. The hospital anxiety and depression scale. Occup Med (Lond). 2014;64(5):393-4.

PMid:25005549

10. Snaith RP. The hospital anxiety and depression scale. Health Qual Life Outcomes. 2003;1:29.

PMid:12914662

11. Rudy M, Widyadharma PE, Adnyana IM. Reliability Indonesian Version of the Hospital Anxiety and Depression Scale (HADS) of Stroke Patients in Sanglah General Hospital Denpasar. Berlin: ResearchGate; 2015.

12. Dahlan MS. Statistics for Medicine and Health: Descriptive, Bivariate, and Multivariate, Complete with Applications Using SPSS. 6th ed. Jakarta: Indonesian Epidemiology; 2014. Dahlan MS. Linear Regression. Series 10 Issue 2. Jakarta: Indonesian Epidemiology; 2018.

13. Bazian. Women are More Likely to Suffer from Anxiety than Men. Available from: https://www.nhs.uk/news/mental-health/womenare-more-likely-to-suffer-from-anxiety-than-men. [Last accessed on 2016 Jun 07]. https://doi.org/10.1787/888933574190

14. Remes O, Brayne C, Linde R, Lafortune L. A systematic review of reviews on the prevalence of anxiety disorders in adult populations. Brain Behav. 2016;6(7):e00497. https://doi. org/10.1002/brb3.497

PMid:27458547

15. Zhua Z, Xua S, Wang H. COVID-19 in Wuhan: Sociodemographic characteristics and hospital support measures associated with the immediate psychological impact on healthcare workers. EClinicalMedicine. 2020;24:100443. https://doi.org/10.1016/j. eclinm.2020.100443

PMid:32766545 